\title{
Human Herpesvirus 1 Positive
}

National Cancer Institute

\section{Source}

National Cancer Institute. Human Herpesvirus 1 Positive. NCI Thesaurus. Code C141249.

An indication that human herpesvirus 1 has been detected in a sample. 